\title{
Prevalence of and risk factors for late diagnosis of HIV infection in Brazilian infants and children
}

\author{
Lígia Mara Dolce de Lemos ${ }^{[1]}$, Andrew Anglemyer ${ }^{[2]}$, Victor Santana Santos ${ }^{[1]}$, \\ Ricardo Queiroz Gurgel ${ }^{[3]}$ and George Williams Rutherford ${ }^{[2]}$
}

[1]. Departamento de Enfermagem, Universidade Federal de Sergipe, Aracaju, Sergipe, Brasil. [2]. Department of Epidemiology and Biostatistics and Global Health Sciences, University of California, San Francisco, USA. [3]. Departamento de Medicina, Universidade Federal de Sergipe, Aracaju, Sergipe, Brasil.

\begin{abstract}
Introduction: Late human immunodeficiency virus (HIV) diagnosis is an important cause of HIV-related morbidity and mortality in infants and children. Methods: This retrospective cohort study of HIV-infected children diagnosed in Sergipe, in northeastern Brazil, between 2002 and 2011 aimed to determine the prevalence of and risk factors for late HIV diagnosis. Results: Of 55 infants and children with confirmed infection, $42(76.5 \%)$ were diagnosed at $\geq 12$ months old. No antiretroviral prophylaxis during delivery (OR 5.48, 95\% CI 1.11-32.34) was associated with late diagnosis. Conclusions: More than $75 \%$ of cases were diagnosed late. Efforts are needed to improve early HIV diagnosis in infants.
\end{abstract}

Keywords: HIV. Infant diagnosis. Vertical transmission. Polymerase chain reaction.

Late diagnosis of human immunodeficiency virus (HIV) infection is an important cause of HIV-related morbidity and mortality in infants and children ${ }^{(1)}$ and represents a serious missed opportunity for early initiation of antiretroviral treatment (ART), which has proven to be very effective in reducing HIVrelated morbidity and mortality in infants and children ${ }^{(1)(2)(3)}$. For example, early mortality in HIV-infected infants was $4 \%$ when ART was initiated at a median age of 7 weeks, compared with $16 \%$ when ART was initiated according to a threshold for cluster of differentiation 4 (CD4) percentage or clinical disease progression $^{(2)}$. Current World Health Organization (WHO) guidelines recommend that ART be started in all infants and children diagnosed with HIV at $\leq 24$ months of age regardless of CD4 percentage or WHO clinical stage ${ }^{(4)}$.

The North and Northeastern regions of Brazil, which include the poorest nine states of the country, have been disproportionately affected by HIV, with much higher HIVspecific mortality rates than the rest of the country ${ }^{(5)}$. In these regions, HIV has spread primarily through heterosexual intercourse, with subsequent substantial numbers of HIVexposed and infected infants.

Sergipe is one of the nine states in Northeastern Brazil, with a population of 2,068,017 and 34,016 births in 2010 . Infant mortality was 18.2 per 1,000 live births in 2010 , which was higher than the median for Brazilian states ${ }^{(6)}$. Sergipe has

Corresponding author: Dra. Ligia Mara Dolce de Lemos. Av. Cláudio Batista s/n, 49048-010 Aracaju, Sergipe, Brasil.

Phone: 5579 3246-6893; Fax: 5579 2105-1813

e-mail: ligiadolce@gmail.com

Received 22 October 2014

Accepted 20 January 2015 a predominantly generalized HIV epidemic, and 3,131 cases of acquired immunodeficiency syndrome (AIDS) in adults and adolescents have been reported since $1987^{(7)}$. The estimated HIV prevalence among women attending antenatal clinics is $0.42 \%{ }^{(8)}$. Among children $<5$ years old, the incidence of AIDS has decreased considerably in recent years from 2.75 cases per 100,000 per year in 2005 to 0.6 cases per 100,000 per year in $2011^{(9)}$.

This study aimed to determine the prevalence of and risk factors for late HIV diagnosis in infants in the State of Sergipe in Northeastern Brazil.

We conducted a retrospective cohort study of HIV-infected infants and children diagnosed in Sergipe between January 1, 2002, and December 31, 2011, when human immunodeficiency virus deoxyribonucleic acid (HIV DNA) was available at 6 weeks of age, as recommended by the Brazilian Ministry of Health. We included individuals considered HIV exposed based on their mother's diagnosis and followed their records until their diagnosis of infection, to identify whether it was a late diagnosis.

We compiled data from the National Information System for Reportable Diseases [Sistema de Informações de Agravos de Notificação (SINAN)], the National Mortality Information System [Sistema de Informação sobre Mortalidade (SIM)], the state laboratory database (viral load tests), and ambulatory medical records from the Federal University of Sergipe and Center of Medical Specialties [Centro de Especialidades Médicas de Aracaju (CEMAR)] for human immunodeficiency virus/sexually transmitted diseases/acquired immunodeficiency syndrome (HIV/STD/AIDS) in Aracaju. When information was incomplete in the chart, we attempted to interview mothers for missing data using a standardized data collection instrument. 
The primary outcome variable of late diagnosis was defined as a virological diagnosis (HIV DNA testing) or a clinical or postmortem diagnosis at $>12$ months of age. We compared these cases to those in infants who had a serological diagnosis or clinical or post mortem diagnosis at $\leq 12$ months of age.

Predictor variables included infant and maternal sociodemographic and clinical factors. For the infants, we recorded sex, date of delivery, breastfeeding history, date of HIV infection diagnosis, date of AIDS diagnosis, date of death, clinical stage of HIV infection, and ART history. For the mothers, we recorded educational level, antiretroviral history (during prenatal care and delivery), timing of HIV infection diagnosis (before pregnancy, during pregnancy, during delivery, after delivery), number of prenatal visits ( $<6$ visits or $\geq 6$ visits), and clinical stage of HIV infection.

We collected all data on a standard form and entered them into a database using Epi Info 3.5.2 [Centers for Disease Control (CDC), Atlanta, GA, USA]. We examined differences in proportions using Fisher's exact test for distributions with fewer than 5 events expected per cell. We calculated unadjusted odds ratios (OR) and $95 \%$ confidence intervals $(\mathrm{CI})$ to examine differences between infants who were and were not diagnosed virologically at $>12$ months of age. We conducted descriptive analyses using Statistical Package for the Social Sciences (SPSS) version 13 (SPSS Inc., Chicago, IL, USA) and bivariate analyses using Stata 8.0 (Stata Corporation, College Station, TX, USA).

We obtained informed consent from parents for interviews. The Ethics and Research Committee of the Federal University of Sergipe approved the study (registration number 0183.0.107.000-10).

Of the 485 infants exposed to HIV in Sergipe during the study period, $55(11.3 \%)$ were diagnosed with HIV infection. Of these 55 infants, seven (12.7\%) had died, and 42 (76.4\%) were more than 12 months old at the time of diagnosis. Of the seven deaths, two were diagnosed virologically at $\leq 12$ months old, and five were diagnosed at $>12$ months of age (OR 1.34, 95\% CI 0.11-9.69) (Table 1). Two of the infants who died were diagnosed on the day of death or postmortem (3.5 months old and 8.9 months old). Of the 13 (25.6\%) diagnosed virologically at $\leq 12$ months of age, four were diagnosed at 6-12 months of age.

No mother received ART (as opposed to antiretroviral prophylaxis) during pregnancy or in the immediate postpartum period. Of the $12(41.8 \%)$ mothers who did not receive antiretroviral prophylaxis during pregnancy, eight infants were diagnosed at $>12$ months old; however, lack of antiretroviral prophylaxis was not significantly related to late diagnosis. Not receiving antiretroviral prophylaxis during delivery (OR 5.48, 95\% CI 1.11-32.34, $\mathrm{p}=0.03$ ) was, however, associated with late diagnosis. Lack of prenatal care and breastfeeding were not associated with late diagnosis (Table 1).

The timing of HIV diagnosis was reported for 42 (76.4\%) mothers. Twenty (47.6\%) were diagnosed with HIV after their babies were born, six (14.3\%) during delivery, and 16 (38.1\%) before or during pregnancy. The infants of women diagnosed during delivery were more likely to have been diagnosed virologically at $\leq 12$ months of age than those of women diagnosed before or during pregnancy $(5 / 11$ vs. $1 / 31, p=0.0028$,
Fisher's exact test); this was not true for those diagnosed before or during pregnancy $(4 / 11$ vs. $12 / 31, \mathrm{p}=1.00)$. Additionally, only seven $(21.9 \%)$ infants of 32 mothers who received antiretroviral prophylaxis during pregnancy, four (14.8\%) of 27 mothers who received intrapartum antiretroviral prophylaxis, and six (40\%) of 15 infants who received neonatal prophylaxis were diagnosed with HIV at $\leq 12$ months of age despite the availability of DNA polymerase chain reaction testing.

More than three-quarters of infants and children diagnosed with HIV infection in Sergipe in a recent 10-year period (2002-2011) were diagnosed after one year of age. Late diagnoses might be associated with the fact that screening for HIV occurred for only $67 \%$ of the $76 \%$ of women who received prenatal care during the antenatal period in Sergipe from 1990 to $2011^{(8)}$.

This study used data beginning in 2002, when Brazil adopted early infant diagnosis; more than half of the women had been were diagnosed before their infants were born, and most received antepartum or intrapartum antiretroviral prophylaxis. The failure to employ early virological testing to diagnose and treat these exposed infants resulted in a substantial number of missed opportunities to improve clinical outcomes in these children ${ }^{(2)}{ }^{(10)}$. Furthermore, the prevalence of late diagnosis would likely be higher if stricter definitions of early diagnosis were used, such as using a cut-off age of $\leq 6$ months or excluding infants diagnosed at or near death ${ }^{(10)}$, instead of the definition of $\leq 12$ months of age, which was based on molecular diagnostic tests in the present study.

Interestingly, six mothers who had not received prenatal care did receive antiretroviral prophylaxis during pregnancy, which underscores the lack of coordination between prenatal and HIV treatment services. It is not clear why infants and children were not tested. Our study population was predominantly lowincome, was poorly educated, and had difficultly accessing health services. A large proportion of women was not diagnosed until the postpartum period and would not necessarily have known to have their infant diagnosed. Additionally, as the majority of HIVinfected infants and children are asymptomatic after birth and during early infancy, mothers may not seek care for their children or be reticent to reveal their own infection status to pediatric providers. Moreover, a dedicated pediatric HIV treatment service does not exist at the Reference Center in Sergipe, and children's and mothers' services have not been linked.

Our study has some limitations. While the data were collected from a universal notification system, which increases the external validity, registry data suffer from incompleteness ${ }^{(8)}$. Additionally, the exposed cases and deaths might have been underestimated, because prior to 2000, most pediatric HIV infections in Sergipe were diagnosed in infants and children who presented with symptomatic disease rather than through screening; therefore, some infants might not have been diagnosed. Additionally, the exposed cases and deaths might have been underestimated, because prior to 2000, most pediatric HIV infections in Sergipe were diagnosed in infants and children who presented with symptomatic disease rather than through screening; therefore, some infants might not have been diagnosed. 
TABLE 1 - Predictors of late diagnosis in HIV-infected infants by age at diagnosis, Sergipe, Brazil, $2002-2011$.

\begin{tabular}{|c|c|c|c|c|}
\hline & $\begin{array}{l}\text { Diagnosed virologically at } \\
\quad>12 \text { months old }\end{array}$ & $\begin{array}{l}\text { Diagnosed virologically } \\
\text { at } \leq 12 \text { months old }\end{array}$ & & \\
\hline Variables & $\%$ & $\%$ & Odds ratio $(95 \% \mathrm{CI})$ & $\mathrm{p}$ value \\
\hline
\end{tabular}

Maternal variables

Area of residence $(\mathrm{n}=44)$

urban (1)

rural (2)

$\begin{array}{cc}34 & 77.3 \\ 1 & 2.3\end{array}$

8

18.1

Referent

Educational level $(n=41)$

illiterate
$<8$ years
8 years
$>8$ years

$\begin{array}{cc}7 & 17.0 \\ 11 & 26.8 \\ 10 & 24.4 \\ 6 & 14.7\end{array}$

Timing of diagnosis $(n=42)$

before pregnancy

during pregnancy

during delivery

after delivery

through child's diagnosis

Antenatal care $(n=43)$

no

yes

$$
5
$$

1

12.4

$12 \quad 28.6$

$6 \quad 14.3$

$16 \quad 37.2$

$16 \quad 37.2$

Stage of HIV infection $(n=54)$

symptomatic

$29 \quad 53.7$

$12 \quad 22.2$

asymptomatic

ARV prophylaxis during antenatal care $(n=44)$

$$
\text { yes }
$$

$25 \quad 56.8$

7

15.9

13.0

4.9

9.8

0.0

2.4

4.07 (0.05-342.07)

NS

no

$8 \quad 18.2$

Lost to follow up $(n=47)$

yes

32

68.1

$$
11
$$

23.4

2.4

7.1

11.9

4.8

0.0

$\begin{array}{ll}4 & 8.5\end{array}$

0

0.0

20.9

Referent

$4.35(0.73-47.67)$

0.09

no

ARV prophylaxis during delivery $(n=43)$

yes

23

53.5

$$
4
$$

9.3

18.6

$3.84(0.23-250.9)$

NS

$1.26(0.13-17.49)$

NS

$0.00(0.00-4.67)$

NS

$0.60(0.01-14.46)$

NS

no

$8 \quad 18.6$

8

$2.89(1.20-1844.1)$

NS

$1.16(0.1-78.5)$

NS

$0.00(0.00-52.00)$

NS

Mode of delivery $(n=39)$

vaginal

$\begin{array}{ll}19 & 48.7 \\ 9 & 23.1\end{array}$

10.3

Referent

caesarean section

$9 \quad 23.1$

4

17.9

$3.56(0.69-21.31)$

NS

Infant variables

$\operatorname{Sex}(n=55)$

$$
\text { male }
$$

female

$\begin{array}{ll}19 & 34.5 \\ 23 & 41.8\end{array}$

5

9.1

Referent

14.6

$1.31(0.32-6.01)$

NS

Continue... 
TABLE 1 - Continuation.

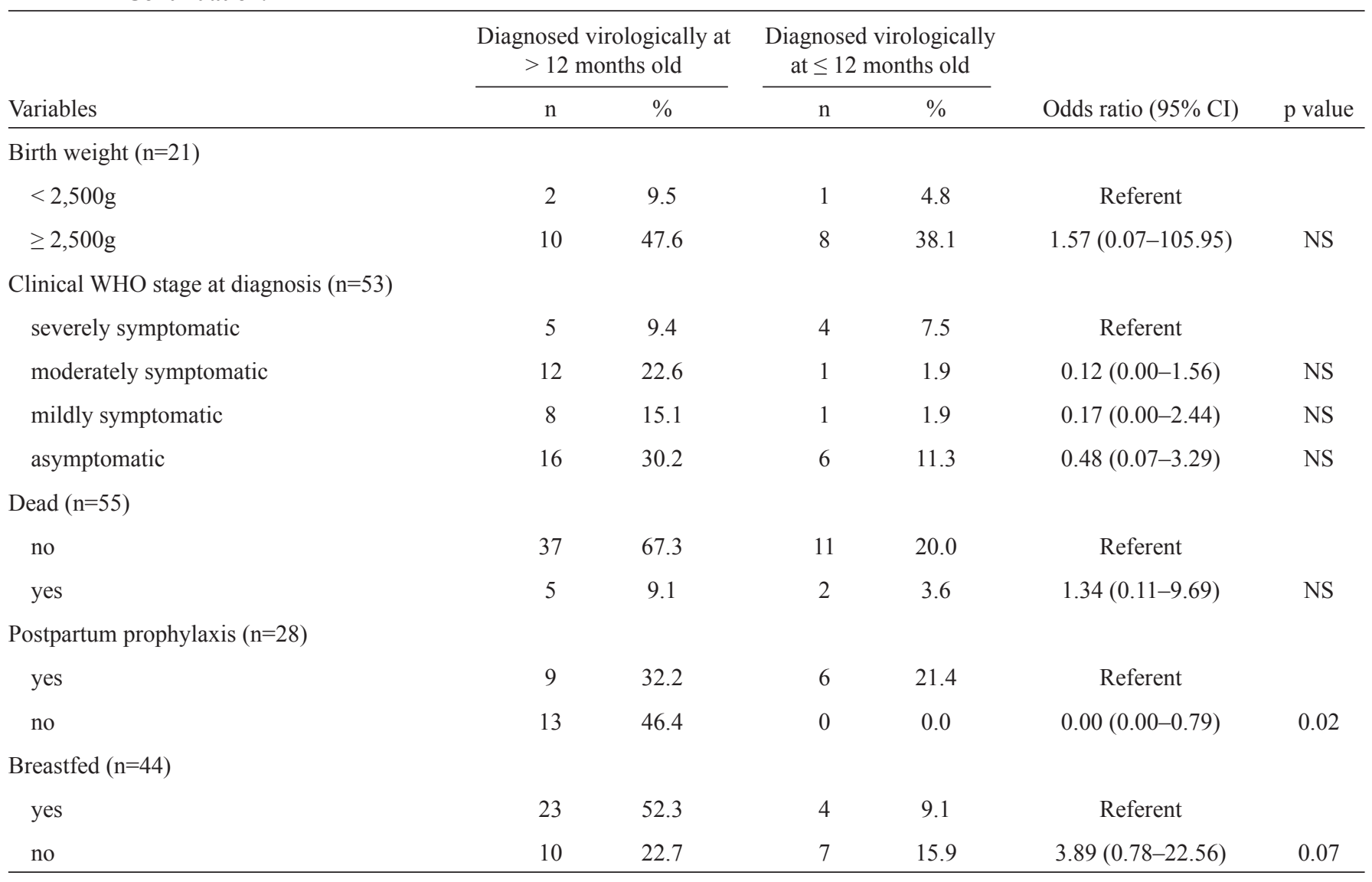

HIV: human immunodeficiency virus; CI: confidence interval; NS: not significant; ARV: antiretroviral; WHO: World Health Organization. The number of pregnant women or infants/children for each variable may not equal 55 due to missing information.

However, late diagnosis was and likely continues to be a significant problem in Sergipe, with more than three quarters of cases diagnosed late during the study period. To facilitate early diagnosis and treatment of infected infants, we recommend that screening of infants should be routine in early pediatric care, not only for those who are known to have been exposed to HIV but also for those whose exposure status is unknown because their mothers have not been tested.

\section{ACKNOWLEDGMENTS}

The authors wish to thank the health services for facilitating the data collection and especially the following students who assisted us with data collection: Gabriella Souza Duarte, Nágla Galvão Regis Martins, Thaísa Fonseca Siqueira Rocha, and Marcus Vinícius da Conceição.

\section{CONFLICT OF INTEREST}

The authors declare that there is no conflict of interest.

\section{FINANCIAL SUPPORT}

This work was supported by the Brazilian Conselho Nacional de Desenvolvimento Científico e Tecnológico and grants from the U.S. National Institutes of Health and Fogarty International Center [International Clinical, Outcomes and Health Services Research Training Award Brazil Scientists Program (D43 TW05799-01) and AIDS International Training and Research Program (D43 TW000003)].

\section{REFERENCES}

1. Wamalwa D, Benki-Nugent S, Langat A, Tapia K, Ngugi E, Slyker JA, et al. Survival benefit of early infant antiretroviral therapy is compromised when diagnosis is delayed. Pediatr Infect Dis J 2012; 31:729-731.

2. Violari A, Cotton MF, Gibb DM, Babiker AG, Steyn J, Madhi SA, et al. Early antiretroviral therapy and mortality among HIVinfected infants. N Engl J Med 2008; 359:2233-2244.

3. Johnson LF, Davies M-A, Moultrie H, Sherman GG, Bland RM, Rehle TM, et al. The effect of early initiation of antiretroviral 
treatment in infants on pediatric AIDS mortality in South Africa: a model-based analysis. Pediatr Infect Dis J 2012; 31:474-480.

4. World Health Organization (WHO). Guidelines on HIV and Infant Feeding 2010: Principles and Recommendations for Infant Feeding in the Context of HIV and a Summary of Evidence. Geneva: WHO; 2010.

5. Matida LH, Ramos Jr AN, Heukelbach J, Sañudo A, Succi RCM, Marques HHS, et al. Improving survival in children with AIDS in Brazil: results of the second national study, 1999-2002. Cad Saude Publica 2011; 27 (supl I):93-103.

6. Ministério da Saúde, Departamento de Informática do Sistema Único de Saúde (DATASUS). Consolidação do Sistema de Informações sobre Nascidos Vivos - 2011. Brasília: Ministério da Saúde; 2011. (Cited 2014 October 22). Available at: http://tabnet. datasus.gov.br/cgi/tabcgi.exe?sinasc/cnv/nvSE.def
7. Ministério da Saúde. Boletim epidemiológico Aids/DST. Brasília, DF: Ministério da Saúde; 2012 p. 25. (Cited 2014 October 22). Available at: http://www.aids.gov.br/sites/default/files/anexos/ publicacao/2012/52654/boletim_jornalistas_pdf_22172.pdf

8. Lemos LMD, Duarte GS, Martins NGR, da Silva FJCP, Ilozue C, Gurgel RQ. Estimating the number of HIV-positive pregnant women in Sergipe, Brazil, using capture-recapture. AIDS Care 2013; 25:691-694.

9. Lemos LMD, Lippi J, Rutherford GW, Duarte GS, Martins NGR, Santos VS, et al. Maternal risk factors for HIV infection in infants in northeastern Brazil. Int J Infect Dis 2013;17:e913-e918.

10. Tejiokem MC, Faye A, Penda IC, Guemkam G, Ateba Ndongo F, Chewa G, et al. Feasibility of early infant diagnosis of HIV in resource-limited settings: the ANRS 12140-PEDIACAM study in Cameroon. PLoS One 2011; 6:e21840. 